\title{
Lymphocyte responses to DR1/4 restricted peptides in rheumatoid arthritis
}

\author{
Margot A Skinner, Lisa Watson, Arie Geursen, Paul L J Tan
}

\begin{abstract}
Objective-To determine whether analog and unrelated DR1/4 binding peptides alter DR1/4 restricted responses of peripheral blood lymphocytes (PBL) from patients with rheumatoid arthritis (RA).

Methods-PBL from 25 patients with RA and 12 healthy controls were cultured with DR1/4 restricted peptides of the influenza haemagglutinin, amino acids 307-319 (HA) and matrix proteins, amino acids 17-29 (IM). Responses were determined by ${ }^{3} \mathrm{H}$-thymidine uptake proliferation assays and limiting dilution analysis. Competitor peptides were analogs HA$R_{312}$ and $H A-K_{313}$ differing from $H A$ by one amino acid at the 312 or 313 position respectively or unrelated peptides which bind to DR1/4.
\end{abstract}

Results-The responses of eight patients with RA to the two stimulatory influenza peptides did not differ significantly from controls and this was confirmed by the frequency estimate of $T$ cells in PBL which responded to $H A$ (mean frequency: 1 in $9.0 \times 10^{4}, n=5$, in DR1/4+ RA patients, 1 in $7.6 \times 10^{4}, n=5$, in DR1/4+ healthy controls). DR1/4 binding analogs of the HA peptide inhibited HA specific peptide responses of PBL from patients with $R A$ and controls. Inhibition was also detected with unrelated peptides which bind to DR1/4 but to which the individual did not respond.

Conclusion-Similar responses to two DR1/4 restricted peptides were observed in patients with RA and controls. Both antigen analog- and unrelated peptidemajor histocompatibility complexes (MHC) can result in the inhibition of antigen specific responses in multiclonal human lymphocyte populations. However, an analog peptide may be stimulatory in some individuals. These results provide some initial data for the development of a rational approach to MHC-specific immunomodulation in rheumatoid arthritis.

(Ann Rheum Dis 1994; 53: 171-177)

The contribution of cell mediated immunity to joint inflammation and destruction in rheumatoid arthritis (RA) is poorly understood but there is evidence of a role for $T$ cellmediated immune responses in the pathogenesis of this disease. ${ }^{1}$ Immunohistological examination of the synovium has shown a prominent infiltrate of lymphocytes, the majority of which are activated $T$ cells. ${ }^{2}$ In addition, several experimental treatment strategies which act primarily through their effect on $\mathrm{T}$ cells are reported to be effective in the treatment of RA. ${ }^{13}$

The association of RA with major histocompatibility genes is well established ${ }^{4}$ and the HLA DR4 (DRB1*04) and DR1 (DRB1*01) genes involved is well documented. ${ }^{5}$ Disease susceptibility has been localised to the third hypervariable region of the $\beta$ chain of DR and in white groups is most commonly associated with Dw4 (DRB1*0401), containing the amino acid sequence LLEQKRAA at positions $67-74$ and VG at residues $85-86 . .^{5}$ This disease-associated epitope is present in Dw4 (DRB1 $\left.{ }^{\star} 0401\right)$, the most frequent DR subtype in white groups. ${ }^{5}$ Dw14.2 (DRB1*0408), Dw15 (DRB1*0405) and DR1 $1\left(\mathrm{DRB} 1{ }^{\star} 0101\right)$ have a single substitution at position 71 , where a lysine replaces the arginine and Dw14.1 (DRB1*0404) has this sequence in the 67-74 region. These alleles also confer disease susceptibility particularly in ethnic groups where Dw4 is a less common allele. ${ }^{67}$

The role of the LLEQKRAA sequence in determining disease susceptibility to RA is not understood at present. This sequence lies within the peptide antigen binding groove of the MHC molecules. Little is known about the influence these residues have on $\mathrm{T}$ cells which recognise peptides and which may be involved in immune regulation in RA. Peptides which bind to such DR1/4 molecules may have a role in causing or perpetuating the disease. Thus peptides that are DR1/4 restricted can be used to analyse $\mathrm{T}$ cell responses dependent on the disease associated genes, and may be useful for comparison when studying putative disease associated antigens. Several investigators have used high affinity MHC-binding peptides to inhibit $T$ cell activation by blocking the antigen-binding site of MHC molecules. ${ }^{8} 9$ It follows that unrelated DR1/4-binding peptides can potentially block the antigen presenting site of the disease associated MHC Class II molecules and thus the cascade of molecular events leading to the activation of arthritogenic $T$ cells may be prevented.

Peptides which bind to DR1/4 have been described and include, residues 307-319 of the influenza haemagglutinin, ${ }^{10}$ residues $17-29$ of the influenza matrix protein ${ }^{10}$ residues $1-15$ of the 19-kd protein of Mycobacterium tuberculosis $(\mathrm{MT})^{1112}$ and residues $38-50$ of the $18-\mathrm{kd}$ 
Mycobacterium leprae protein $(\mathrm{ML} 3)^{13}$ in addition to the naturally processed peptides derived from MHC-related molecules. ${ }^{14}$ Competition studies using analogs of such peptides, to inhibit human peptide-specific $T$ cells, have been successful but have utilised peptide-specific $T$ cell lines and clones. Before such techniques can be used to develop an immunotherapeutic approach to $R A$ the lymphocyte responses of patients with $\mathrm{RA}$ to these peptides must be determined. In previous work, we analysed the responses of lymphocytes from patients with RA to the DR1/4 restricted epitope of $M T .^{12}$ In this report we describe the responses of peripheral blood lymphocytes (PBL) from healthy individuals and patients with RA to three other DR1/4 restricted peptides and show that proliferative responses can be altered by both non-stimulatory peptide analogs which bind to DR1/4 and by unrelated peptides to which an individual does not respond.

\section{Patients and methods}

PATIENTS

A total of $25 \mathrm{DR} 1 / 4+$ patients with RA and 12 DR1/4+ healthy age-matched controls were entered into the study. All patients had seropositive erosive $\mathrm{RA}$ and fulfilled the American College of Rheumatology revised criteria for RA. ${ }^{15}$ There were 18 women and seven men aged 30-81 years. Their duration of disease ranged from one to 52 years. Most patients had at least four inflamed joints; eight patients had from 0 to 3 inflamed joints. Two patients were taking no medication, two patients took paracetamol, 17 patients took non-steroidal anti-inflammatory drugs (NSAIDs), eight patients had prednisone (2-10 mg/day), and 21 patients received antirheumatic agents (8 took methotrexate, 5 D-penicillamine, 3 intramuscular sodium thiomalate, 3 sulfasalazine and 2 azathioprine). PBL from all patients and controls were DR1/4 typed either with the assistance of M Roberts (Auckland Regional Blood Centre) or by a PCR technique. ${ }^{7}$ The HLA status was confirmed by DR4 subtyping using a single stranded conformational polymorphism technique $^{16}$ recently developed in our laboratory for the HLA-DR4 group of alleles.

\section{PEPTIDES}

The amino acid sequences in brackets are given as single letter codes. The synthetic peptides from influenza haemogglutinin, amino acids 307-319 (PKYVKQNTLKLAT) and matrix, amino acids 17-29 (SGPLKAEIAQRLE), were synthesised by the Joint Protein Structure Laboratory, Ludwig Institute for Cancer Research, Melbourne, Australia. The analog peptides derived from $\mathrm{HA}^{8}$ were monosubstituted derivatives, $H A-R_{312}$, where the glutamine at position 312 was replaced by an arginine (PKYVKRNTLKLAT) or HA-K ${ }_{313}$, where the asparagine at position 313 was replaced by a lysine (PKYVKQKTLKLAT) and were synthesised by Chiron Mimotopes
Pty, Clayton, Australia. The $M$ leprae 18-kd peptide ML3, amino acids $31-50$ (DAWREGEEFVVEFDLPGIK) and the $M$ tuberculosis 19-kd peptide, D3, amino acids 31-50 (SGETTTAAGTTASPGAASGPK), were synthesised by the Protein Chemistry Unit, Massey University, New Zealand. All peptides were purified by reverse-phase high performance liquid chromatography and were greater than $92 \%$ pure.

\section{LYMPHOCYTE PROLIFERATION ASSAY}

Heparinised peripheral blood was subjected to Ficoll-Hypaque (Pharmacia, Piscataway, NJ) gradient separation. Lymphoid cells were harvested, washed three times in RPMI (Life Technologies, Grand Island, NY) medium and viable cells counted using trypan blue. The cells were cultured at $2 \times 10^{5}$ per well in 96 well round bottom plates (Nunc, Denmark) in a total volume of $200 \mu \mathrm{R}$ RMI supplemented with $5 \%$ heat inactivated autologous serum (culture medium) and stimulated in triplicate with phytohemagglutinin (PHA) at $1 \mu \mathrm{g} / \mathrm{ml}$, peptide (HA, IM, ML3), or medium alone. Peptides were added to give a final concentration of $10 \mu \mathrm{g} / \mathrm{ml}$, unless otherwise stated, a dose in the optimal range for stimulating $\mathrm{T}$ cell proliferation.

For competition studies, $2 \times 10^{5} \mathrm{PBL}$ were preincubated with the blocking peptide at 10 $\mu \mathrm{g} / \mathrm{ml}$, unless otherwise stated, in a total volume of $190 \mu \mathrm{l}$ before the addition of the stimulating peptide. Preliminary experiments indicated that blocking could be detected although to a lesser extent when both stimulatory and blocking peptides were added simultaneously but a four hour pre-incubation with the blocking peptide gave more consistent results and was therefore used throughout. A control peptide from the $19-\mathrm{kd}$ protein of $M$ tuberculosis (D3) to which DR1/4+ individuals do not respond ${ }^{12}$ was included as a negative control in competition experiments and did not affect the response to stimulating peptides.

Cultures were incubated at $37^{\circ} \mathrm{C}$ in $5 \% \mathrm{CO}_{2}$ in air for 5-6 days and pulsed with $0.25 \mu \mathrm{Ci}$ ${ }^{3} \mathrm{H}$-thymidine (Dupont/NEN, Boston, MA) for the last 18 hours. Cells were thus harvested during the peak response to peptide (4-6 days) but not at the peak of the PHA response. They were harvested onto filters and uptake of radiolabel was determined using either an LKB Beta plate system (Wallac, Turku, Finland) or PHD cell harvester (Cambridge Instruments Inc, MA) and a liquid scintillation counter. The results are expressed as cpm or as the stimulation index (SI), which represents the counts per minute (cpm) obtained with peptide or PHA stimulation divided by the $\mathrm{cpm}$ in cultures of cells with medium alone. The standard deviations were usually less than $20 \%$ of the SI values. In all cases, $1.7 \mathrm{X}$ SI exceeded 2 standard deviations of the background.

LIMITING DILUTION ANALYSIS

Graded numbers of PBL (from $6.4 \times 10^{1}$ to $2 \times 10^{5}$ ) were cultured with $5 \times 10^{4}$ autologous 
$\gamma$-irradiated (40 Gy) PBL feeder cells in round bottom 96 -well plates with peptide $(10 \mu \mathrm{g} / \mathrm{ml})$. Eleven dilutions were used for each experiment with 24 microcultures per concentration. No exogenous growth factors were added. Cultures containing only feeder cells plus peptide or responder cells alone were included as controls. Plates were maintained at $37^{\circ} \mathrm{C}$ in an atmosphere of $5 \% \mathrm{CO}_{2}$ in air for six days and harvested as described above. Microcultures were scored as positive for proliferation to the peptide when the cpm was >3SD above the background. Minimal estimates of the frequencies of proliferating $T$ cells were calculated by analysis of the Poisson distribution relationship between the number of responding cells cultured and the percentage of negative wells. At least four experimental points were used to fit data to the zero order term of the Poisson equation by the least squares method and results are expressed as the values determined by linear regression analysis as described previously ${ }^{17}$ where the slope is the frequency ( $f$ ). Values of $p$ were determined from the coefficient of correlation and thus indicate whether the data follows 'single-hit' kinetics.

\section{Results}

PROLIFERATIVE RESPONSES TO DR $1 / 4$ RESTRICTED PEPTIDES

Responses to the DR1/4 restricted peptide from the 19-kd protein of $M$ tuberculosis are similar in controls and patients with RA. ${ }^{12}$ Experiments were carried out with other DR1/4 restricted peptides from influenza to determine whether this was a general phenomenon particularly as analogs of the haemagglutinin peptide are candidate blocking agents. PBL from $8 \mathrm{DR} 1 / 4$ positive patients with RA and controls were cultured at $2 \times 10^{5}$ cells per well with $10 \mu \mathrm{g} / \mathrm{ml} \mathrm{HA}$ or IM for six days. The data are shown in table 1 . Although proliferation in response to peptides differed in magnitude between individuals, there was no significant difference between the responses of the DR1/4+ patients with RA and controls. PBL from two patients with $R A$ responded to only one of the peptides, while PBL from one

Table 1 Comparison of maximum proliferative responses of peripheral blood lymphocytes from patients with $R A$ and healthy controls to influenza matrix (IM) and haemagglutinin (HA) peptides. *

\begin{tabular}{|c|c|c|c|c|}
\hline Subjects & Nil & $I M$ & $H A$ & PHA \\
\hline RAl & 191 & $169(0.9)$ & $126(0.7)$ & $64188(336)$ \\
\hline RA2 & 318 & $453(1 \cdot 4)$ & $478(1.5)$ & $15843(50)$ \\
\hline RA3 & 664 & $887(1 \cdot 3)$ & $1358(2 \cdot 0)$ & $13372(20)$ \\
\hline RA4 & 633 & $999(1 \cdot 6)$ & $1912(3.0)$ & $53908(85)$ \\
\hline RA5 & 1785 & $2988(1 \cdot 7)$ & $5579(3.1)$ & $49674(28)$ \\
\hline RA6 & 421 & $1108(2 \cdot 6)$ & $864(2 \cdot 1)$ & $9332(22)$ \\
\hline RA7 & 148 & $468(3 \cdot 2)$ & $691(4 \cdot 7)$ & 7845 (53) \\
\hline RA8 & 207 & $1659(8.0)$ & $1515(7 \cdot 3)$ & 23087 (111) \\
\hline $\mathrm{Cl}$ & 518 & $501(1 \cdot 0)$ & $646(1 \cdot 2)$ & 9341 (18) \\
\hline $\mathrm{C} 2$ & 596 & $571(1 \cdot 0)$ & $430(0 \cdot 7)$ & 8806 (15) \\
\hline $\mathrm{C} 3$ & 1234 & $2452(2 \cdot 0)$ & $2150(1 \cdot 7)$ & $4073(3 \cdot 3)$ \\
\hline $\mathrm{C} 4$ & 389 & $870(2 \cdot 2)$ & $885(2 \cdot 3)$ & 5949 (15) \\
\hline C5 & 99 & $233(2 \cdot 4)$ & $338(3.4)$ & $10311(104)$ \\
\hline C6 & 280 & $662(2 \cdot 4)$ & 3319 (12) & $12970(46)$ \\
\hline C7 & 254 & $1681(6 \cdot 6)$ & $1324(5 \cdot 2)$ & 26651 (105) \\
\hline $\mathrm{C} 8$ & 470 & $6146(13)$ & $2411(5 \cdot 1)$ & 8390 (18) \\
\hline
\end{tabular}

$\star$ Values are the mean cpm of triplicate cultures in which the SD did not exceed $20 \%$ and (stimulation index). Data with phytohaemagglutinin (PHA) are included for comparison. patient and two control subjects did not respond to both peptides. The one patient (RA1) whose PBL did not respond to both peptides was aged 30 years and was taking no medication. PBL from the other patient taking no medication (RA8, aged 68 ) responded to both peptides. All other patients whose PBL showed responses were taking NSAIDs and long-acting antirheumatic agents. The patients who were 'responders' included those with four to 26 inflamed joints and three patients with none, two or three inflamed joints.

The frequency of precursor cells proliferating in response to HA was determined by limiting dilution analysis. Increasing numbers of PBL were cultured with $\mathrm{HA}$ for six days and wells containing proliferating cells were scored. The frequency of precursor cells which responded to HA ranged from 1 in $3.52 \times 10^{4}$ to 1 in $1.49 \times 10^{5}$ in DR1/4+ RA patients and 1 in $6.19 \times 10^{3}$ to 1 in $1.94 \times 10^{5}$ in DR1/4+ controls. For comparison, two DR1/4- RA patients and three DR1/4- controls were included in the analysis. In 5 of $6 \mathrm{DR} 1 / 4$ individuals ( $R A$ patients + controls), the data did not follow 'single hit' kinetics nor fit the Poisson distribution $(p>0 \cdot 1)$ as the precursor frequencies were lower than estimated in table 2. However, precursor frequencies to HA are included in table 2 to demonstrate the difference in response between DR1/4+ [mean (SD) $\mathrm{f}=1$ in $\left.8 \cdot 2 \times 10^{4}(6 \cdot 40), \mathrm{n}=10\right]$ and DR1/4- individuals [mean (SD) $\mathrm{f}=1$ in $2.92 \times 10^{6}(2.41), \mathrm{n}=5$ ]. In summary these data demonstrate that the responses of PBL from DR1/4+ RA patients to the two DR1/4 restricted peptides from influenza do not differ to those from healthy age-matched controls.

RESPONSES TO HA 307-319 AND MONOSUBSTITUTED ANALOGS

Mono-substituted analogs of HA 307-319 have been shown to bind to DR1 and inhibit HA stimulated proliferation of a DR1restricted HA specific $T$ cell clone but do not stimulate the $T$ cell receptor (TCR) of this clone. ${ }^{8}$ Two such analogs, HA-R $\mathrm{R}_{312}$ and HA$\mathrm{K}_{313}$ were synthesised and tested for their ability to stimulate PBL to proliferate. Of the $14 \mathrm{DR} 1 / 4+$ individuals tested, $3 \mathrm{RA}$ patients responded to $\mathrm{HA}$ and both analogs (SI $>1 \cdot 7$ ), 2 RA patients responded to $\mathrm{HA}$ and the HA$R_{312}$ analog, and the remaining 7 patients and 2 controls responded only to the HA peptide. The results from individuals who responded to one or both analogs are shown in table 3 . The three patients with RA, RA1, 20, and 21, who only responded to $\mathrm{HA}$ are included for comparison.

EFFECT OF ANALOGS ON THE PBL RESPONSE TO HA

The peptides $\mathrm{HA}-\mathrm{R}_{312}$ and $\mathrm{HA}-\mathrm{K}_{313}$ were tested for their ability to inhibit multiclonal $\mathrm{T}$ cell responses specific for HA. Dose-response data using a constant concentration of stimulatory peptide with increasing amounts of HA- $R_{312}$ competitor peptide is shown in fig 1 . 
Table 2 The frequency $(f)$ of peripheral blood lymphocytes proliferating to the DR1/4 restricted influenza haemagglutinin $307-319$ peptide $(H A)^{\star}$

\begin{tabular}{llllll}
\hline Patient & Reciprocal off & $p$ & Controls & Reciprocal off & $p$ \\
\hline DR1/4+ & & & & & \\
RA9 & $3.52 \times 10^{4}$ & 0.01 & C2 & $6.19 \times 10^{3}$ & 0.01 \\
RA10 & $5.82 \times 10^{4}$ & 0.001 & C7 & $1.17 \times 10^{4}$ & 0.01 \\
RA4 & $5.88 \times 10^{4}$ & 0.001 & C6 & $7.24 \times 10^{4}$ & 0.001 \\
RA11 & $1.49 \times 10^{5}$ & 0.001 & C9 & $9.68 \times 10^{4}$ & 0.05 \\
RA12 & $1.49 \times 10^{5}$ & 0.05 & C8 & $1.94 \times 10^{5}$ & 0.01 \\
DR114- & & & & & $>0.1$ \\
RA13 & $3.44 \times 10^{5}$ & $>0.1$ & C10 & $2.04 \times 10^{6}$ & $>0.01$ \\
RA14 & $5.49 \times 10^{6}$ & $>0.1$ & C11 & $1.25 \times 10^{6}$ & $>0.1$ \\
\hline
\end{tabular}

*The frequency, $\mathrm{f}$, was derived from the zero order term of the Poisson distribution by linear regression analysis with $\mathrm{p}$ values derived from the correlation coefficient.

Table 3 Responses to the influenza haemagglutinin 307-319 peptide and two monosubstituted analogs

\begin{tabular}{lrrrr}
\hline Subjects & Nil & $H A$ & $H A-R_{3 l 2}$ & \multicolumn{1}{c}{$H A-K_{3 l 3}$} \\
\hline RA15 & 894 & $2734(3 \cdot 1)$ & $2227(2 \cdot 5)$ & $866(1 \cdot 0)$ \\
RA16 & 84 & $215(2 \cdot 6)$ & $180(2 \cdot 1)$ & $259(3 \cdot 1)$ \\
RA17 & 521 & $1638(3 \cdot 1)$ & $3447(6 \cdot 6)$ & $6021(11 \cdot 6)$ \\
RA18 & 1674 & $3656(2 \cdot 2)$ & $4386(2 \cdot 6)$ & $6156(3 \cdot 7)$ \\
RA19 & 378 & $3424(9 \cdot 1)$ & $1692(4 \cdot 5)$ & $318(0 \cdot 8)$ \\
RA1 & 642 & $2016(3 \cdot 1)$ & $938(1 \cdot 4)$ & $693(1 \cdot 1)$ \\
RA20 & 43 & $364(8 \cdot 5)$ & $69(1 \cdot 6)$ & $57(1 \cdot 4)$ \\
RA21 & 577 & $8099(14 \cdot 1)$ & $640(1 \cdot 1)$ & $543(0 \cdot 9)$ \\
\hline
\end{tabular}

Values are the mean cpm of triplicate cultures in which the SD did not exceed $20 \%$ and (stimulation index). All patients were DR4+. RA15 not able to subtype, all others were DRB $1 \star 0401$. The data of RA 19, 1,20 and 21 are also included in figure 2 .

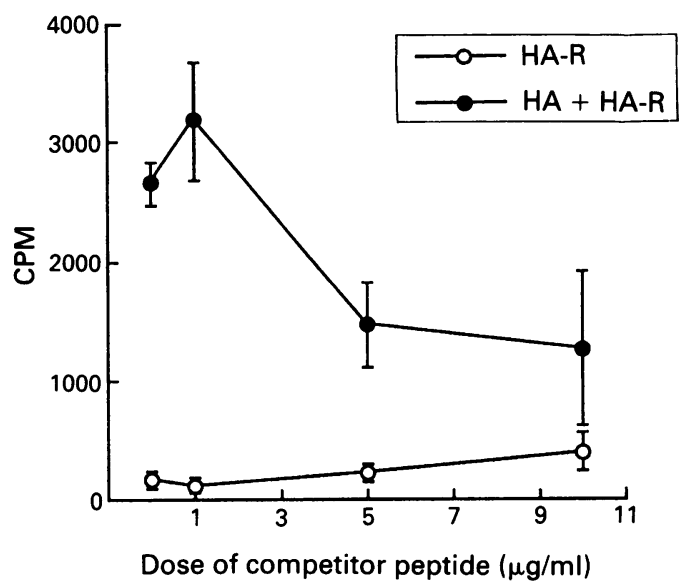

Figure 1 A single amino acid substitution of influenza haemagglutinin 307-319 peptide (HA) renders it nonstimulatory but effective as an inhibitor of an $H A$-specific response. The $H A$ analog $H A-R_{312}$ was tested for its capacity to stimulate a proliferative response in peripheral blood lymphocytes (O) or to inhibit a response to $10 \mu \mathrm{g} / \mathrm{ml}$ $H A(\bullet)$ in a homozygous $D R 4+\left(D R B 1{ }^{*} 0401\right.$ and $\left.D R B 1^{\star} 0404\right) R A$ patient. The mean cpm of triplicate cultures with $S E$ are shown.

Effective inhibition was noted with $5-10 \mu \mathrm{g} / \mathrm{ml}$ of competitor peptide. PBL from DR1/4+ RA patients and controls were thus incubated with $10 \mu \mathrm{g} / \mathrm{ml} \quad \mathrm{HA}-\mathrm{K}_{313}$ or $\mathrm{HA}-\mathrm{R}_{312}$ before stimulation with $10 \mu \mathrm{g} / \mathrm{ml} \mathrm{HA}$. The results obtained from 8 patients with RA and two controls are shown in fig 2. Of the 10 individuals tested in this experiment, none responded to the $\mathrm{HA} \mathrm{K}_{313}(\mathrm{SI}<1 \cdot 7)$ and two of 10 responded to the HA-R $\mathrm{R}_{312}(\mathrm{SI}>1 \cdot 7)$. The $\mathrm{HA}-\mathrm{K}_{313}$ analog inhibited the response to $\mathrm{HA}$ in all 10 of 10 individuals whereas the HA-R ${ }_{312}$ analog inhibited responses in eight of 10 . Thus in this sample of patients and controls, the HA$\mathrm{K}_{313}$ analog appeared to be the more effective inhibitor. In one patient with RA (subject 19, fig 2) who responded to HA-R $R_{312}$, the response

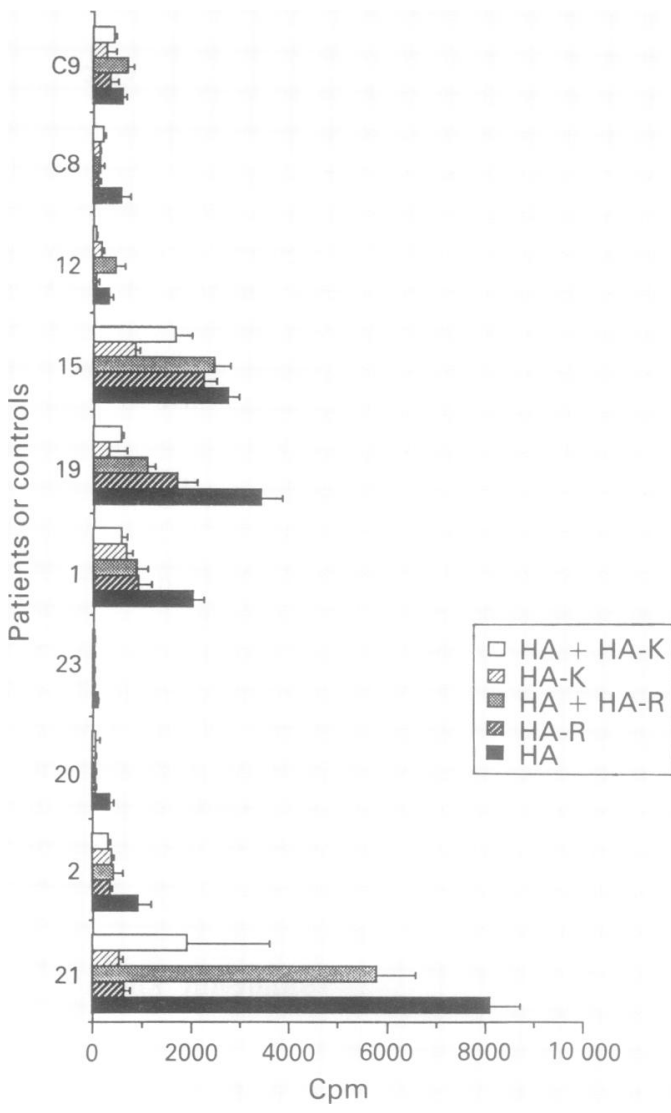

Figure 2 The inhibition of peripheral blood lymphocyte responses to influenza haemagglutinin peptide 307-319 (HA) by analog peptides. Two $H A$ analogs $H A-R_{312}$ and $H A-K_{313}$ were tested for their capacity to inhibit the responses of peripheral blood lymphocytes from 10 individuals, $8 R A$ patients and 2 healthy controls to $H A$. Cultures contained the peptides as indicated. The results are shown as the mean cpm of triplicate cultures with $S D$. The mean cpm of cultures without peptide was 204, 291, 43, $31,642,378,894,136,88$, and 202 for subjects 21,2 $20,23,1,19,15,12, C 8$ and $C 9$ respectively.

to both this analog and HA together was less than the response to either individual peptide alone. From the data it is clear that these HA analog peptides can inhibit HA specific responses of multiclonal $\mathrm{T}$ cells.

COMPETITION BETWEEN UNRELATED DR1/4 RESTRICTED PEPTIDES

Peptides of different sequences have been shown to compete for presentation to $\mathrm{T}$ lymphocytes by the same MHC molecules both in vitro and in vivo in the mouse $\mathrm{e}^{18} 19$ and in human $\mathrm{T}$ cell clones. ${ }^{18}$ To test whether this effect can be demonstrated in human PBL, these cells were cultured with $10 \mu \mathrm{g} / \mathrm{ml} \mathrm{HA}, 10$ $\mu \mathrm{g} / \mathrm{ml}$ of a DR $1 / 4$ restricted peptide from the $18-\mathrm{kd}$ protein of $M$ leprae (ML3) or $10 \mu \mathrm{g} / \mathrm{ml}$ of both peptides. Most individuals responded to HA but not to ML3. In these individuals the simultaneous culture of PBL with ML3 resulted in inhibition of the HA response (fig 3). In only three of 37 individuals tested, such as RA patient 24, a response to ML3 was detected in the absence of a response to HA. In this situation, culture with both HA and ML3 resulted in the inhibition of the ML3 response (fig 3). Such data supports the notion that competition between unrelated DR1/4 


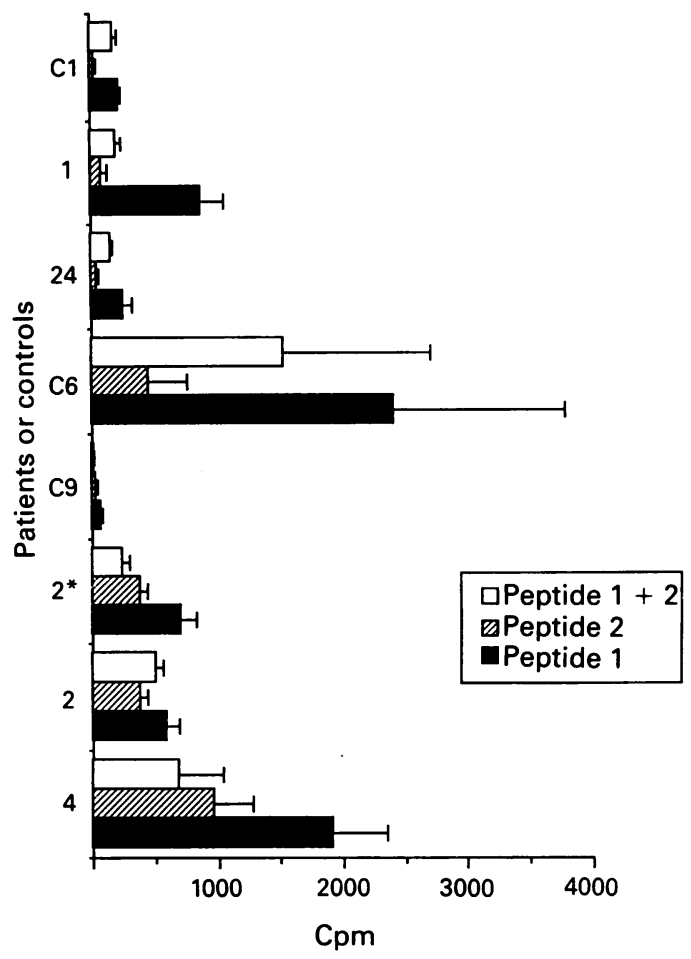

Figure 3 An unrelated peptide can inhibit the response to another DR1/4 restricted peptide. The results are expressed as mean cpm of triplicate cultures with $S D$ where peptide 1 is the stimulatory peptide and peptide 2 is the inhibitory peptide. For $R A$ patients 4, 2 and controls $C 9$ and $C 6$, peptide 1 was $H A$ and peptide 2 was $M L 3$. For RA patien $2^{*}$, peptide 1 was IM. For RA patients 24,1 and control $C 1$, peptide 1 was ML3 and peptide 2 was $H A$. The mean cpm in cultures without peptide was $633,318,22,318,42$, 247 and 16 for subjects 4, 2, C9, C6, 24, 1, and C1 respectively.

restricted peptides can occur in fresh human lymphocyte populations.

\section{Discussion}

New strategies for the immunotherapy of RA can be developed if the antigen presenting function of the disease-associated HLA molecule is examined. Our intention is to extend the hypothesis that antigen presentation by $\mathrm{DR} 1 / 4$ is critical to the pathogenesis of RA and can be blocked by DR1/4 binding peptides. Analog and unrelated peptides can inhibit specific $T$ cell responses to stimulatory peptides both in vitro and in vivo. ${ }^{18} 19$ Nevertheless, little is known about the effect of such inhibitors on the responses of multiclonal populations of human $T$ cells. In this report we have examined responses to DR1/4 restricted peptides in patients with RA and demonstrate that PBL T cell proliferative responses to these peptides can be inhibited by other peptides which bind to DR1/4.

To study the DR1/4 binding site, the ideal peptide is one which elicits a consistent response. T lymphocytes important in RA have presumably been activated and thus responses to an antigen that most individuals are exposed to each winter was selected. Responses of PBL to two DR1/4 restricted peptides from influenza virus were detected in five of eight patients with RA and six of eight healthy controls. One patient responded only to the haemagglutinin peptide. The absence of a detectable response in some individuals may be due to the low frequency of antigen-specific precursor cells in the circulation which could change from time to time as suggested previously. ${ }^{12}$ Analysis of the frequency of HA peptide specific precursors demonstrated that this could vary from 1 in $6.19 \times 10^{3}$ to 1 in $1.94 \times 10^{5}$ in DR4+ individuals. The range in precursor frequency also presumably accounts for the variation in the magnitude of the response to the two peptides and is dependant on factors such as previous exposure to influenza. Even so, the responses were consistent in that those of the healthy control group did not differ significantly from those of the patient group. Comparative frequency analysis of $T$ lymphocytes has been useful in multiple sclerosis patients where the frequency of myelin basic protein reactive $T$ cells in the blood is $10-100$ times higher than in controls and in patients with RA or other neurological diseases. ${ }^{20}$ Such analysis of DR1/4 restricted peptide responses may lead to a better understanding of the antigens involved in causing or prolonging the disease should a high precursor frequency be detected in the RA patient group.

Inhibition of DR $1 / 4$ restricted responses by competing peptides can be facilitated by analog peptides that differ from the stimulating peptide by as little as one amino acid or by peptides that are completely unrelated except for their MHC binding characteristics. Analogs of the HA peptide and the unrelated DR1/4 restricted peptide ML3 were both efficient at inhibiting the response of PBL to HA. Although it has been presumed that the mode of inhibition is MHC blockade, ${ }^{21}$ recent evidence suggests that antigen analog-MHC complexes may act as antagonists of the $\mathrm{T}$ cell receptor. ${ }^{22}$ An ideal peptide for immunotherapeutic development would presumably be one which has the ability not only to bind to DR1/ 4 but also to block responses at the level of the TCR. However, the design of such a peptide for RA may not be possible until the peptide which causes or perpetuates the disease is known. At present, it may be useful to consider naturally processed peptides such as the ones derived from MHC-related molecules that are bound to DR1. ${ }^{14}$

To assay for suitable candidates, the inhibitory peptide must itself not illicit a proliferative response, although for the purpose of blocking the presentation of a self peptide involved in the pathogenesis of RA it may not be important as to whether there is a response to the blocking peptide or not. The analogs of the HA peptide stimulated a response in only five of $14 \mathrm{DR} 1 / 4+$ individuals and responses to ML3 were rare in the white New Zealand population (unpublished observation). In an individual who responded to the $H A-R_{312}$ analog, less proliferation occurred when both $\mathrm{HA}$ and $\mathrm{HA}-\mathrm{R}_{312}$ were included than in response to either peptide alone. It is difficult to envisage how MHC blockade could account for this result. A more likely mechanism might involve inhibition at the level of the TCR and several possibilities 
can be considered. Firstly, induction of a hyporesponsive state ${ }^{2324}$ in the $T$ cell could be induced by delivery of a negative signal. Secondly, only partial activation of the TCR could occur as shown by lymphokine production in the absence of proliferation. ${ }^{25}$ Thirdly, the inhibitory capacity of the peptideMHC complexes on the TCR could occur in the absence of any signal transduction comparable, in effect, to a pharmacological receptor antagonist. This third mechanism is supported by the work of De Magistris et $a l^{22}$ who achieved more effective inhibition of HAspecific $T$ cell clones with similar analog peptides than with unrelated peptides.

Specific analog peptides have been used in an animal model of autoimmune disease, experimental allergic encephalitis (EAE), to prevent responses to the disease-causing peptide present in myelin basic protein..$^{26}{ }^{27} \mathrm{As}$ the peptide which causes or perpetuates RA is unknown it is more appropriate to consider blocking the DR1/4 binding site with an unrelated peptide. Competitive inhibition of the formation of autoantigenic peptide-MHC may interfere with the activation of $T$ cells responsible for the disease particularly as DR4 Dw4 $T$ cell recognition of self antigens has been reported in the rheumatoid synovial compartment. ${ }^{28}$ Our results demonstrate that this type of blocking is feasible. It was possible to detect inhibition by two unrelated DR1/4 restricted peptides, ML3 and HA, by selecting individuals who whould respond to only one of the peptides. Thus the ML3 peptide would inhibit responses to $\mathrm{HA}$ in $\mathrm{HA}$ responding subjects, whilst HA would inhibit ML3 specific responses in individuals responding to the ML3 peptide. Preliminary studies using synovial fluid $T$ cells indicate that responses by these cells can be inhibited in a similar way (unpublished observation).

Biochemical studies of peptide binding to Class II MHC molecules in vitro showed that competition between peptides occurred at a single site. ${ }^{29}$ This approach has since been used to assign MHC contact residues of several antigenic peptides. ${ }^{30}$ Competition between peptides has been predicted to take place in vivo and is proposed as a mechanism for the observed immunodominance of particular $\mathrm{T}$ cell determinants within complex protein antigens. The hen egg lysozyme system has been used as a model for studying this competition in vivo in the mouse. From results obtained with this system Adorini et $a l^{31}$ proposed that 100 nmoles of an efficient competitor peptide is sufficient to completely saturate the available MHC Class II binding sites in each mouse. Thus in vivo competition in humans should not require exceedingly large amounts of peptide. In vitro studies allow the identification of peptides capable of blocking DR $1 / 4$ responses and provide the basis for designing peptides for future in vivo studies.

The result of competitor peptide administration may not simply be the inhibition of a single specific peptide response. Cohen and Young ${ }^{32}$ propose that a regulated autoimmune network exists in healthy individuals and that autoimmunity results from the loss of suppressing elements. If competitor peptides change the immunodominance of an autoantigen or alter the balance of dominant $T$ cell clones they may allow the dysregulated autoimmune network to normalise. Future work aimed at the analysis of TCR V $\alpha$ and V $\beta$ gene usage in multiclonal rheumatoid lymphocyte populations exposed to DR1/4 binding peptides, may help us to further understand the outcome of peptide competition.

We thank the rheumatologists Drs M J Butler, D E Caughey, P J Gow, R R Grigor, F Grinlinton, H Hart and N Lynch for contributing patients for this study, Mrs S Yeoman for assistance at the Rheumatology Clinics, $\mathrm{Mr} \mathrm{J}$ Peake for assistance with the DR4 subtyping and Dr S J M Skinner for help with editing the manuscript. Supported in part by the for help with editing the manuscript. Supported in part by the Arthritis Foundation of New Zealand, the Auckland Medical Zealand.

1 Kingsley G, Pitzalis C, Panayi G S. Immunogenetic and cellular immune mechanisms in rheumatoid arthritis: relevance to new therapeutic strategies. $\mathrm{Br} \mathcal{F}$ Rheumatol 1990; 29: 58-64.

2 van Boxel J A, Paget S A. Predominantly T-cell infiltrate in rheumatoid synovial membrane. N Engl f Med 1975; 293: $517-20$.

3 Strober S, Holoshitz J. Mechanisms of immune injury in rheumatoid arthritis: evidence for the involvement of $T$ cells and heat-shock protein. Immunol Rev 1990; 118: 233-55.

4 Stastny P. Association of B cell alloantigen DRw4 with rheumatoid arthritis. N Engl f Med 1978; 298: 869-71.

5 Wordsworth B P, Lanchbury J S S, Sakkas L I, Welsh K I Panayi G S, Bell J I. HLA-DR4 subtype frequencies in rheumatoid arthritis indicate that DRB1 is the majo susceptibility locus within the HLA class II region. Proc Natl Acad Sci USA 1989; 86: 10049-53.

6 Gao X, Brautbar C, Gazit E, et al. A variant of HLA DR4 determines susceptibility to rheumatoid arthritis in subset of Israeli Jews. Arthritis Rheum 1991; 34: 547-51.

7 Tan P L J, Farmiloe S, Roberts M, Geursen A, Skinner M A. HLA DR4 subtypes in New Zealand Polynesians. Predominance of Dw13 in the Zealand Dw15 in the healthy

8 Rothbard J B, Busch R, Howland $\mathrm{K}$ et al. Structural analysis of a peptide-HLA class II complex: identification of critical interactions for its formation and recognition by $T$ cell receptor. Int Immunol 1989; 1: 479-86.

9 O'Sullivan D, Sidney J, Appella E, et al. Characterization of the specificity of peptide binding to four DR haplotypes. F Immunol 190; 145: 1799-808.

10 Rothbard J B, Lechler R I, Howland K, et al. Structural model of HLA-DR 1 restricted $T$ cell antigen recognition. Cell 1988; 52: 515-23.

11 Lamb J R, Rees A D M, Bal V, Ikeda H, Wilkinson D, de Vries R R P, Rothbard J B. Prediction and identification of an HLA-DR-restricted T cell determinant in the 19 of an HLA-DR-restricted $\mathrm{T}$ cell determinant in the 19 1988; 18: $973-6$.

12 Tan P L J, Farmiloe S, Young J, Watson J D, Skinner M A. Lymphocyte responses to DR4/1 restricted peptides in rheumatoid arthritis. The immunodominant epitope on the 19-kd Mycobacterium tuberculosis protein. Arthriti Rheum 1992; 35: 1419-26.

13 Oftung F, Shinnick T M, Mustafa A S, Lundin K E A Godal T, Nerland A H. Heterogeneity among human T cell clones recognizing an HLA-DR 4 Dw4-restricted epitope from the $18 \mathrm{kDa}$ antigen of Mycobacterium leprae defined by synthetic peptides. F Immunol 1990; 144: 1478-83.

14 Chicz R M, Urban R G, Lane W S, et al. Predominant naturally processed peptides bound to HLA-DR1 are naturally processed peptides bound to HLA-DR1 are derived from MHC-related molecules and

15 Arnett F C, Edworthy S M, Bloch D A, et al. The American Rheumatism Association 1987 revised criteria for the Rheumatism Association 1987 revised criteria for the classification of 1988 ; 31 : $315-24$.

16 Spinardi L, Mazars R, Theillet C. Protocols for an improved detection of point mutations by SSCP. Nucl Acids Res detection of point

17 Skinner M, Marbrook J. Regulation of cytotoxic lymphocyte responses. 1. Interactions between concanavalin $A$ and cell growth factors. Cell Immunol 1984; 85: 519-30.

18 Buus S, Sette A, Colon S M, Miles C, Grey H M. The relationship between major histocompatibility complex (MHC) restriction and the capacity of Ia to bind to immunogenic peptides. Science 1987; 235: 1353-58.

19 Adorini L, Muller S, Cardinaux F, Lehmann P V, Falcioni F, Nagy $Z$ A. In vivo competition between self peptides and foreign antigens in $\mathrm{T}$ cell activation. Nature 1988; 334: 623-25. 
20 Chou Y K, Bourdette D N, Offner H, et al. Frequency of $T$ cells specific for myelin basic protein and myelin proteolipid protein in blood and cerebrospinal fluid in multiple sclerosis. 7 Neuroimmunol $1992 ; 38$ : 105-14.

21 Grey H M, Sette A, Lamont A. Biologic significance and therapeutic implication of antigen/MHC interactions. Clin Immuno Immunopathol 1989; 53: S47-52.

22 De Magistris M T, Alexander J, Coggeshall M, et al. Antigen analog-major histocompatibility ' complexes act as antagonists of the T cell receptor. Cell 1992; 68:625-34.

23 Lamb J R, Skidmore B J, Green N, Chiller J M Feldmann $M$. Induction of tolerance in influenza virusmmune $\mathrm{T}$ lymphocyte clones with synthetic peptides of influenza hemagglutinin. $\mathcal{F} \operatorname{Exp}$ Med 1983; 157: 1434-47.

24 Schwarz R H. A cell culture model for T lymphocyte clona anergy. Science 1990; 248: 1349-56.

25 Evavold B D, Allen P M. Separation of IL-4 production from Th cell proliferation by an altered $\mathrm{T}$ cell receptor ligand. Science 1991; 252: 1308-10.

26 Wraith D C Smilek D E, Mitchell D J, Steinman I McDevitt $\mathrm{H} O$. Antigen recognition in autoimmune encephalomyelitis and the potential for peptide mediated immunotherapy. Cell 1989; 59: 247-55.

27 Urban J L, Horvath S J, Hood L. Autoimmune T cells: immune recognition of normal and variant peptide epitopes and peptide based therapy. Cell 1989; 59: epitopes and peptide based therapy. Cell 1989; 59:

28 Devereux D, O'Hehir R E, McGuire J, van Schooten W C A Lamb J R. HLA DR4Dw4-restricted T cell recognition of self antigen(s) in the rheumatoid synovial compartment. Int Immunol 190; 3: 635-40.

29 Babbitt B P, Matsueda G, Haber E, Unanue E R, Allen P M Antigenic competition at the level of peptide-Ia binding Proc Natl Acad Sci USA 1986; 83: 4509-13.

30 Jorgenson J L, Reay P A, Ehrich E W, Davis M M Molecular components of T cell recognition. Ann Rev Immunol 1992; 10: 835-73.

31 Adorini L, Nagy Z A. Peptide competition for antigen presentation. Immunol Today 1990; 11: 21-24.

32 Cohen I R, Young D B. Autoimmunity, microbial immunity and the immunological homunculus. Immunol Today 1991; 12: 105-10. 